Please do not remove this page

RMIT

UNIVERSITY

\title{
Selling Drugs on Darkweb Cryptomarkets: Differentiated Pathways, Risks and Rewards
}

Martin, James; Munksgaard, Rasmus; Coomber, Ross; Demant, Jaköb; Barratt, Monica

https://researchrepository.rmit.edu.au/esploro/outputs/9921887124401341/filesAndLinks?institution=61 RMIT_INST\&index=null

Martin, J., Munksgaard, R., Coomber, R., Demant, J., \& Barratt, M. (2020). Selling Drugs on Darkweb Cryptomarkets: Differentiated Pathways, Risks and Rewards. British Journal of Criminology, 60(3), 559-578. https://doi.org/10.1093/bjc/azz075

Document Version: Accepted Manuscript

Published Version: https://doi.org/10.1093/bjc/azz075

Repository homepage: https://researchrepository.rmit.edu.au

(c) 2019 The Author(s). Published by Oxford University Press on behalf of the Centre for Crime and Justice Studies (ISTD).All rights reserved.

Downloaded On 2023/04/26 22:58:24 +1000 
Selling drugs on darkweb cryptomarkets: differentiated pathways, risks and rewards

(Corresponding author) Martin, James - School of Social Sciences, Swinburne University of Technology

Address: John St, Hawthorn, Victoria, Australia 3122

Ph: (03) 92145801

Email: jrmartin@swin.edu.au

Munksgaard, Rasmus - École de Criminologie, Université de Montréal

Coomber, Ross - 1) Department of Sociology, Social Policy and Criminology, University of Liverpool; 2) Griffith Criminology Institute, Griffith University; 3) School of Justice, Queensland University of Technology, Brisbane, Australia.

Demant, Jakob - Department of Sociology, University of Copenhagen

Barratt, Monica J. - 1) Social and Global Studies Centre, RMIT University; 2) National Drug and Alcohol Research Centre, UNSW Sydney

Word count: 9972 inclusive of all sections 


\title{
Selling drugs on darkweb cryptomarkets: differentiated pathways, risks and rewards
}

\begin{abstract}
Cryptomarkets, anonymous online markets where illicit drugs are exchanged, have operated since 2011, yet there is a dearth of knowledge on why people use these platforms to sell drugs, with only one previous study involving interviews with this novel group. Based on 13 interviews with this hard to reach population, and data analysis critically framed from perspectives of economic calculation, the seductions of crime, and drift and techniques of neutralisation, we examine the differentiated motivations for cryptomarket selling. Throughout the interviews we observe an appreciation for the gentrified norms of cryptomarkets, and conclude that cryptomarket sellers are motivated by concerns of risks and material rewards, as well as nonmaterial attractions in a variety of ways that both correspond with, and differ from, existing theories of drug selling.
\end{abstract}

\section{Introduction}

Since 2011, cryptomarkets have increasingly been used to sell illicit drugs. Cryptomarkets, also known as DNMs (darknet markets) or anonymous online markets, are a subgenre of a broader ecosystem of illicit online markets (Barratt \& Aldridge, 2016; Martin 2014a; 2014b). Sellers referred to as vendors - register themselves and sell goods to buyers in exchange for a commission paid to the platform administrators, who in turn provide the necessary infrastructure in which the marketplace will act as a mediator for the exchange of goods for currency (Morselli et al., 2017; Moeller et al., 2017). Organisationally, these markets mimic the design, functionality and organisation of licit online platform economies like eBay or Amazon. Contrasting them to social drug supply or open drug markets, Aldridge \& Décary-Hétu (2016) suggest that these markets constitute a new type of drug market that is both open and anonymous.

These illicit platform economies are capable of operating in the open by utilising technologies that limit the capabilities of law enforcement to censor internet content or identify buyers, vendors and administrators (Christin, 2013). Specifically, this is achieved by using: a) the Tor network to anonymise internet traffic, b) cryptocurrencies, predominantly Bitcoin, to circumvent censorship by third parties (e.g. credit card institutions), and c) encouraging the use of PGP encryption between actors to secure private communications and verify identities. ${ }^{1}$ Despite their technological sophistication cryptomarkets have continued to grow, with yearly revenues in hundreds of millions (Soska \& Christin, 2015; Kruithof et al., 2016), and the ecosystem of competing markets has shown itself highly resilient to law enforcement interventions (Décary-Hétu \& Giommoni, 2017; Ladegaard, 2018, 2019a, 2019b).

\footnotetext{
${ }^{1}$ More detailed discussions of encryption technologies and technical details may be found in Hutchings and Holt (2017).
} 
The scholarship on cryptomarkets and their users has emphasised their potential to reduce systemic violence (Moeller et al., 2017; Barratt et al., 2016; Aldridge \& Décary-Hétu, 2016, Martin 2019; 2014a; 2014b), and the potential of reputation system to incentivise and reward the supply of high-quality drugs (Aldridge et al., 2018; Hardy \& Norgaard, 2016; Przepiorka et al., 2017). Cryptomarkets thus present as advantageous alternatives to open and closed inperson drug markets which, though they differ extensively, may be rife with violence (Bourgois, 2003; Jacques \& Wright, 2015) and product uncertainty (Cole et al., 2011; Coomber 2006). Relatively little is known about this novel cohort of cryptomarket drug vendors, with most studies in this developing sub-field of research using quantitative approaches to measure surface level metrics such as product availability, sales numbers, prices, country destination, and so on. These studies have revolved around themes such as market competition (Przepiorka et al., 2017; Hardy \& Norgaard, 2016), supply and demand (Aldridge \& Décary-Hétu, 2016; Demant, Munksgaard \& Houborg, 2016), responses to 'crackdowns' (Décary-Hétu \& Giomonni, 2017; Ladegaard, 2019) and other supply-side restrictions (Martin et al., 2018b), and conflict management and predation (Moeller et al., 2017; Morselli et al., 2017).

As research on cryptomarket vendors has typically pre-assumed economic calculations of risk and reward, it has left out the extensively documented non-economic motivations that characterise drug market participants more broadly. Drug market participants are embedded in social relationships, spanning the spectrum from predatory to altruistic, drugs are traded between friends, norms inform behaviour and practices and so forth (Bourgois, 2003; Jacques \& Wright, 2015; Sandberg, 2012), and the choice to sell drugs will rarely present as informed exclusively by economic calculation, but more often as a drifting towards this particular social role motivated by both material and non-material concerns. While the ethical and political concerns of buyers on cryptomarkets are well-documented (e.g. harm reduction, opposition to the war on drugs, libertarianism, Maddox et al., 2016; Munksgaard \& Demant, 2016; Bancroft \& Reid, 2017; Martin, 2014a), such concerns among cryptomarket vendors are yet to be explored. Finally, except for one study by Van Hout \& Bingham (2014), qualitative research that involves interviews with people who sell drugs on cryptomarkets is entirely absent. Consequently, a two-fold research gap exists: a lack of examination of both material and nonmaterial motivations of cryptomarket vendors as well as qualitative research in general.

This paper seeks to bridge this gap through qualitative interviews with cryptomarket vendors where motivations and career pathways surrounding entry into, and persistence within, cryptomarket drug selling are analysed. The article begins by considering pathways into selling drugs generally. We then proceed to discuss method and data employed in the current study, followed by analysis and discussion.

\section{Traditional pathways into selling drugs}

Within the existing literature regarding pathways into selling drugs, we identify three broad theoretical themes that are of particular relevance to this study: economic analyses of seller behaviour; cultural criminological 'seductions' of crime; and the interlinked concepts of drift and techniques of neutralisation. We discuss these below referring to the character of the 'seller' in an abstract sense, but note that differentiation in drug markets and among sellers 
vary extensively across drug types, social backgrounds and social setting (e.g. Jacques \& Wright, 2015; Bourgois, 2003; Taylor \& Potter, 2013; Dwyer \& Moore, 2010).

Of the three theoretical themes, the first - economic analyses - have had the greatest impact on drug and law enforcement policy (Hayward, 2007). The economic approach to understanding involvement in drug selling is perhaps best exemplified in Reuter and Kleiman's (1986) seminal 'risks and prices' paper. Therein the authors explain seller participation in drug markets as the result of two competing forces: financial rewards that incentivise selling drugs, and deterrence that results from physical risks, such as arrest and incarceration, as well as death or injury at the hands of rival sellers or other offenders, along with financial risks, which include loss of product via criminal predation or interception by law enforcement (Reuter \& Kleiman, 1986). The stark motivational calculus at the heart of the economic approach is clear and methodologically, if not empirically, precise: "economic return on dealing = revenue from selling drugs - costs of obtaining the drugs - conventional business costs - non-monetary costs" (Caulkins \& MacCoun, 2003:3). This approach to understanding seller motivation is exclusive in its focus on material risks and rewards and makes explicit that "people sell drugs primarily to make money, not for pathological or ideological reasons" (Caulkins \& MacCoun, 2003:3).

Economic theories of seller behaviour which focus exclusively on economic/material considerations of physical and financial incentives and risk contrast with the seductions of crime. First articulated by Katz (1988), proponents of the seductions of crime, and other similar approaches such as 'edgework' (Lyng, 1990), explicitly reject a narrow on material factors and instead explain seller behaviour as characterised by a particularly non-material form of transgressive hedonism (see also Curcione, 1997; Collison, 1996). From this perspective, selling drugs is not the result of calculative reasoning of present and future earnings weighed against potential risks, but rather is motivated by an exhilarating carnival of visceral emotions and sensations, such as thrill, dominance and status recognition. The risks of violence and other dangers - whether emanating from law enforcement or from others on 'the street' - do not deter sellers, but rather are reinterpreted as offering exciting opportunities to escape the drudgeries, disempowerment and social and economic disenfranchisement inherent to working class life (Collison, 1996; Katz, 1988).

Our third theoretical perspective - drift and techniques of neutralisation - posits that many sellers do not purposively seek to engage in deviancy, but rather ' $d r i f t$ ' back and forth between lawful and unlawful behaviours depending upon circumstances, and their social environment (Matza, 2009; see also Goldsmith \& Brewer, 2015, for an application in the context of cybercrime). The most powerful individual circumstances precipitating drift into selling drugs are personal histories of drug use and non-commercial sharing or 'social supply' of drugs to friends and acquaintances (Coomber \& Moyle 2014; Khoury et al 2010; Reed et al 2007). Both involve a reorientation of personal attitudes towards using and selling drugs, away from one of deviancy towards one of relative normalisation, particularly for many young people for whom drugs are a relatively frequent feature of everyday life (Coomber et al. 2016). Techniques of neutralisation, which enable this drift, are those self-rationalisations that sellers make in order to neutralise the guilt, shame and internal conflicts that accompany their violation of legal and social norms (Matza 2009). All five of the classic techniques of neutralisation - denial of responsibility, denial of injury, denial of victim, appealing to higher 
loyalties and condemning the condemners - have been used to explain why people commence and persist in selling drugs (Jacinto et al 2008; Curcione 1997).

\section{Differentiation}

In spite of the apparently discrete theoretical pathways into selling drugs outlined above, empirical evidence demonstrates that seller motivations are typically complex, sometimes contradictory, and regularly defy neat categorisation. There are not only a range of overlapping pathways into drug supply, but also types of seller, their motivations and roles, and how markets manifest all can, and often do, differ significantly (Coomber, 2015; 2006). Naturally, this differentiation does not preclude the utility of theoretical examinations of seller pathways, though it does render problematic the idea of 'an' archetypal drug seller following ' $a$ ' correspondingly homogenous pathway. In all cases, the highly variable characteristics of the drug market in which they operate shapes how and why sellers enter into and persist in their illegal careers, as well as influences their daily lived experiences as they go about their work.

How the variable characteristics of drug markets influence, or vary alongside with, seller participation is a critical and, as yet, largely unanswered question when considering cryptomarkets. Not only are cryptomarkets novel, they present a unique institutional configuration that differentiates them from other drug markets in a variety of significant ways. These include: participant anonymity; exceptionally large numbers of sellers and buyers; transparency regarding both vendors and the products they sell (type, price, volume, etc.); publicly visible customer feedback and vendor rating systems; market-administered dispute resolution and escrow services; as well as constant geographical separation between market participants (which therefore precludes the possibility of physical violence between them) (Martin et al., 2019).

Given these significant structural differences, differentiated seller pathways and the varying explanatory power of theoretical frameworks across drug markets, we anticipate significant differentiation in how and why people become involved and persist in selling drugs on cryptomarkets compared with other forms of drug supply. A central aim of this research, therefore, is to explore how the structural characteristics of cryptomarkets shape and interact with seller motivations, concerns and lived experiences that are different in terms of risk, as well as material and non-material rewards compared to other forms of in-person drug exchange. Rather than employing one overarching theory, this paper synthesises the various theoretical approaches outlined in the section above, drawing upon each as required to explain different aspects of seller behaviour on cryptomarkets. How this particular form of market differentiation manifests and shapes the careers and daily experiences of vendors, and how our empirical data either validate or diverge from existing theoretical perspectives, will be the main focal points of the subsequent analysis and discussion sections. 


\section{Method}

Our sample of 13 respondents constitute the largest cohort of cryptomarket vendors in published research (c.f., Van Hout \& Bingham 2014). Tzanetakis (2018) found 2,188 vendors on the largest operating cryptomarket AlphaBay between 2015 and 2016. Similarly, PaquetClouston et al. (2018) observed a cumulative number of vendors growing from 692 to 1,582 over 6 months in the same period on the same market. Adding additional criteria, such as separating sellers of non-drug items and acknowledging that vendors can operate multiple profiles, we suggest that the population of active cryptomarket vendors is relatively small, numbered below 2000-3000. This population is distinguished by being suspicious and extraordinarily hard to reach. Recruitment and interview strategies therefore both emphasised and utilised the reputation of the research team and existing contacts, seeking to demonstrate as much technical and subcultural knowledge or 'capital' as possible to gain entry and achieve rapport. Underpinning this approach were the research team's previous qualitative research in the domain, which had made us aware of specific concepts, inside jokes, cultural and social norms.

Public recruitment consisted of an advertisement posted to DeepDotWeb.com, a website that published news relevant for cryptomarket buyers and vendors at the time of recruitment. Given the website's function as an unofficial news organ for the community, this served as an endorsement from its administration (as recommended by Barratt \& Lenton, 2010). This informal support for the research project was aided by a message posted to the blog of Eileen Ormsby, author of the book 'Silk Road' (Ormsby, 2014), who presently remains well-respected in the communities around cryptomarkets. Recruitment advertisements referenced previous scholarly work from the research team and detailed a sophisticated protocol for ensuring the safety and privacy of informants. Several interviewees voiced their appreciation of these endorsements. Participants were offered a compensation for their time of 40 AUD in cryptocurrency which could be received directly or donated to a charity.

The recruitment and interview protocol, while complicated, sought to both demonstrate technical proficiency and establish certainty as to the credentials of the research team (Barratt \& Maddox, 2016). Practically, recruitment necessitated the provision of evidence demonstrating the veracity of the recruitment message (i.e. that it was not a third party impersonating the research team), as well as various encryption protocols, including PGP, which secured all correspondence. Drawing initial inspiration from Van Hout \& Bingham (2014) and Barratt \& Maddox (2016), we established multiple points of communication through which the team could be contacted: accounts on cryptomarkets and associated forums, encrypted instant messaging and email. To ensure privacy and anonymity, all accounts used for communication were isolated to an operating system using full-disk encryption.

Interviews were conducted in the period between March 2017 and March 2018, were semistructured and conducted over synchronous (e.g. instant messaging) or asynchronous (e.g. email, private message systems on forums) communication. The semi-structured approach was chosen to introduce a comparative and integrative element to the analysis, and we specifically crafted interviews in order to allow interviewees to articulate their motivations without being limited by a theoretical understanding of pathways and motivations as being rooted in rationality alone. An original intent of limiting interviews to 1-2 hours had to be 
forsaken because informants were typically occupied with other tasks (e.g. packaging drugs, handling customer complaints and questions). As Barratt (2012) argues, the conversational styles that arise from instant messaging and, in our experience, asynchronous communication like email as well, can be 'impoverished' and 'limited' (p. 566). Consequently, developing rapport with informants was a challenge and, following suggestions from Barratt (2012), we relied on humour, disclosure of personal information and adaptation of linguistic style for this purpose, of which each required extensive knowledge of the domain. Quotes utilised in the analysis were edited for spelling errors but are otherwise verbatim.

The sample is diverse with vendors of cannabis, MDMA, cocaine, NPS, LSD, heroin and dissociatives, representing the wide array of illicit drugs offered by the population (Soska \& Christin, 2015). For reasons of anonymity, basic demographic information (age, geographic location, etc.) was not sought or collected, though we deemed information regarding the scale and approximate revenues earned as relevant contexts for analysis. Conforming to established patterns in quantitative research (Demant et al., 2018) vendors in the cohort predominantly operated from North America or Central and Western Europe. Paquet-Clouston (2018) separate cryptomarket vendors into three groups, of which $90 \%$ "make very few to no sales" (p. 94), with 9\% responsible for $36 \%$ of estimated revenue, and $1 \%$ responsible for the remaining 49\%. In our cohort, we consider two respondents as representative of large-scale distributors (yearly income greater than 100,000 USD), two respondents as 'small-timers' (smaller than 10,000 USD), with the remainder best described as medium-scale (between 10,000 and 100,000 USD). The skewed income distribution within the sample may be ascribed to the fact that some vendors operate under multiple pseudonyms, that their activity is dispersed over several markets, or that they have other revenue streams, or that our recruitment strategy was based on community engagement, something in which not every vendor will participate and which may be most visible to those who are embedded in the online market. Similarly, given how some vendors had difficulty communicating in English or enquired whether interviews could be conducted in another language, we also suggest that language barriers may bias the sample in addition to recruitment being mostly visible for those who are more integrated into the market ecosystem. However, we note that about half of our sample were not native English speakers.

\section{Analysis}

In this section we analyse how vendors account for their use of cryptomarket platforms for drug trading and their pathways into selling on cryptomarkets. We analyse these discourses with reference to the three frameworks previously identified: economic understandings of risk and reward, seductions of crime, and drift and techniques of neutralisation. In the interviews these themes intersect and overlap. The grouping and distinction in this analysis is therefore analytical, rather than empirical.

Throughout the analysis we reference an online and an offline, a distinction that was central in interviews, though possibly affected by the use of these terms in the interview guide. In the context of these interviews, the term 'online' is a placeholder for cryptomarkets, but the term 'offline' may variously refer to street selling, trading between known persons, or social supply. Thus, the concepts function as points of reference but do not imply a rigid division between 
two distinct domains. That is, we acknowledge that offline dealing is likely to involve digitally mediated elements, such as encrypted messaging apps to arrange face-to-face meetings. It is important to acknowledge that online worlds are not easily contained within their own boundaries, communication is multimodal and hybrid (Baym, 2009) and, therefore, the dichotomy implicit in these data may fracture upon closer inspection.

\section{Economic calculation: fewer risks and greater financial rewards}

Consistent with the differentiation in the motivations and career pathways of offline sellers (Coomber, 2015), participants revealed a variety of considerations and supply histories underlying their decisions to sell drugs on cryptomarkets. In relation to risk, however, for most participants, the pathway to selling on cryptomarkets was fairly straightforward and involved an apparently significant element of calculation regarding the perceived risks and financial benefits - an approach commonly associated with economic theories of drug supply (Caulkins \& MacCoun, 2003; Levitt \& Venkatesh, 2000; Reuter \& Kleiman 1986). Amongst the 13 respondents, 7 revealed a history of offline selling before becoming active as suppliers on cryptomarkets. 2 respondents still engaged in offline supply, though no longer at the retail level. For these vendors, a key initial question was why commence selling on cryptomarkets when an offline trade and customer base was already accessible? To this, all respondents consistently offered a clear answer: the potential for significantly higher profits in a context of reduced risk.

Interviewer: So you still sell on DNMs [darknet marketplaces], and prefer that to offline. correct?

Respondent (1): YES. Selling offline is borderline stupid. You can make so much more money online, the risks [in selling outside cryptomarkets] aren't even remotely worth it.

Interviewer: So why did you decide to move business to DNMs?

Respondent (2): Its massively more safe, secure. The risks are drastically lower and the possibilities for great success are huge.

The potential for increased profit expressed by interviewees makes sense since they are not constrained by some of the limitations facing their offline counterparts, in particular having to limit their business to trusted clientele within close physical proximity (e.g. Jacques \& Wright, 2015; Moeller \& Sandberg, 2015; Moeller \& Sandberg, 2019). Being able to conduct anonymous sales to a vast network of online customers massively increases the number of potential transactions that a seller can make, and some respondents reported turning over large volumes of drugs that, in the offline drugs trade, would more typically be associated with suppliers operating at the wholesale or mid-level stages of a distribution network (Morselli, 2001).

Perceptions of risk amongst vendors centred around two inter-related sources: law enforcement and 'shady' customers who either threatened violence themselves or were seen as a potential informers for law enforcement. On a superficial level, these two sources of risk resemble those that are also prevalent for offline sellers (Cross, 2000). However, important 
differences were repeatedly and emphatically pointed out by interviewees. Being able to sell drugs anonymously online without any physical interaction with customers, any one of whom could be an undercover law enforcement agent or potential informer, provided vendors with a sense of distance from both other offenders, as well as from law enforcement. This afforded online vendors a feeling of safety and control that was otherwise absent from offline selling:

Respondent (3): I wanna talk about how much safer this [selling on cryptomarkets] is than dealing drugs in real life. For me it's safer because people who buy drugs are shady and usually live in a shady area. I used to sell out of my apartment or else I wouldn't get the sale and when I did I would be paranoid because driving around with drugs in a bad part of town, pocket full of money, anything could happen. And if someone you sell to gets arrested they are going to ask who the seller is 99\% of the time someone will snitch on you.

Respondent (4): Well, there's risk on both sides [of offline and online selling]. But the main difference is the customer... I feel I have little to no risk being busted vending on DNMs. Because I have so much more control.

Perceptions of reduced risk are understandable given the practical complications associated with investigating, robbing or informing on vendors who sell drugs via cryptomarkets. While law enforcement agencies have routinely stated that they investigate online drug selling, such investigations are more complicated, time-consuming and resource intensive than those offline sellers (Martin, 2014a), particularly when vendors follow sufficient operational security (OPSEC) protocols (Bancroft \& Reid, 2017). Similarly, customers who purchase drugs online do not have the opportunity to physically prey upon vendors, nor do they have sufficient knowledge to inform on suppliers, thereby ameliorating another significant source of risk compared to offline sellers.

While the risk of arrest was considered minimal and manageable by vendors, almost every respondent reported becoming a victim of a 'marketplace exit scam', in which administrators abscond with funds deposited on the cryptomarket (Moeller et al., 2017). As one vendor explained, losing funds in an exit scam is an unfortunate but inevitable reality:

Respondent (5): And of course exit scams etc are part of the risk. I've lost things with Alphabay going down. It is never pleasant. But you have to be aware of those potential risks and have no other choice than accepting them, otherwise close your computer and try something else.

Similarly, every vendor reported having to deal with customers who tried to defraud them. Though they took steps to mitigate these risks, vendors considered this form of predation as an additional unavoidable cost of doing business. As such, vendors identified the same general sources of risk as in offline drug markets - i.e. law enforcement and other market actors (Cross, 2000) - though the former was considered manageable and the latter an unavoidable 'cost of doing business'. As a motivating factor, vendors consistently pointed to the lowered risk from law enforcement, which was intrinsically tied to the level of control they could exercise over their work, namely by increasing the sophistication of their OPSEC. 


\section{Seductions of online selling: empowerment, freedom and transgression}

Accompanying the economic motivations for online selling were more hedonic experiences that transcended dispassionate calculation and more closely resembled the various seductions of crime identified by Katz (1988). Visceral sensations of empowerment, emancipation, transgression and thrill, often contextualised within a milieu of political subversion, were also relayed by participants. For example, when asked about their first purchase as a customer, one vendor began detailing how the ostensibly mundane activity of shipping products was experienced as exhilarating and thrilling:

Respondent (6): Exhilarating... and nerve racking. Seemed so alien. "Drugs? Online? In the post? Naaaah surely not". Plus if I'm honest, my inner reprobate buzzes from it. The rush of chucking a grands worth of drugs into postboxes... unreal man...

Some vendors further stressed subjective experiences of autonomy and emancipation from legal work and bosses as a reward in itself. While much of the work of a vendor is spent with drudgeries (packaging individual shipments whilst 'on auto-pilot', driving to post boxes and handling customer complaints, etc.), one interviewee argued that the principal difference between his new employment and the licit alternative was a sense of autonomy:

RM: The thing about living you wrote. How is this different from a slave job? Respondent (3): This is fun for me I enjoy it. No hours to work I have no boss. RM: What's the fun part? Not the packaging I suppose?

Respondent (3): I guess it's the freedom. I don't mind packaging I guess because I'm doing it for me and not a big corporation.

Respondent (6): Ultimately this is just so me and my bro and a couple of pals can carry on acting like teenagers haha. Fuck proper jobs we wanna play chess blast tunes smoke dope and bang postal packs... I love what I do.

These statements show that alongside the perceptions of increased safety and greater financial rewards, vendors also experience heightened emotional states associated with their offending similar to offline sellers (Collison, 1996), and that there are tangible non-financial rewards associated with their work. Whether interacting with customers on 'the street' or engaging anonymously on a cryptomarket, both enjoy a substantial, non-material rush and can derive longer-term enjoyment from their work.

One significant difference noted by interviewees, however, is that unlike offline sellers, people who sell drugs via cryptomarkets often experienced these emotional highs in a context of physical isolation. Some interviewees with a history of offline dealing missed the public recognition, status and notoriety associated with their previous work, while others relocated their desire for recognition away from 'the street' and towards other members of the darknet 'community':

Respondent (4): I miss hanging with the older guys and having that 
"cool" reputation. But it was over rated and too unpredictable.

Respondent (1): There is nothing like having your word be trusted

on the DNM's. That actually means something.

The interviewees above highlight an intriguing difference between the 'street cred' associated with some forms of offline selling and how a vendor's public status and social interactions are shaped by selling drugs on a cryptomarket. Unlike offline drug supply, which may be linked to status displays and a public 'gangsta' persona (Sandberg, 2012; Topalli et al, 2002; Collison 1996), online dealing is typically decoupled from one's offline identity. This enables vendors the ability to compartmentalise their online offending, separating it from their offline world to the extent of their choosing. A vendor's public profile may therefore be interpreted as a digital mask of sorts, one which enables pseudonymous social participation in online forums and the associated enjoyment of recognition amongst peers and customers, but which can also be removed, thereby affording vendors the freedom to participate in the 'straight', offline world without being identified as an offender.

\section{'Soft seductions': safety, professionalism and gentrified norms}

Vendors also expressed relief and appreciation for operating in a scene in which many of the other perceived downsides of street-level drug selling were absent. Apart from an absence of violence, vendors described their appreciation of the different social organisation and norms of cryptomarkets through concrete examples contrasting the online and offline drug trades. Describing his previous relationship to selling on 'the street', one vendor referred to those operating there as people who "use women as bitches types", criticising antisocial practices of violence, coercion and misogyny that were perceived to be associated with the offline drug economy. These sentiments reveal a desire for less volatile 'softer' seductions amongst interviewees who were often quick to emphasise their preference for safety, stability and courteous engagement over the violence and confrontation that were perceived to be prevalent in the offline drugs trade:

Respondent (7): I hadn't ever thought about selling drugs in any capacity because I dislike violence and it just seemed impossible to be involved in selling drugs in "real life" without running into some sort of confrontation pretty quickly... I was always too scared and slightly nerdy to do that and never really contemplated it seriously until the darknet.

The feelings of relative safety and control expressed by participants, and the perception of a sharp dichotomy between the cryptomarket and the offline drugs trade in terms of reduced risks and greater profitability echo the earlier findings of Van Hout and Bingham (2014) and fit within an orthodox criminological narrative of rational 'push' and 'pull' factors. However, the reduced risk perceived by vendors did not just influence their decision to commence selling at cryptomarkets, they also provided a sense of personal satisfaction and professional identity that differs in some important respects from those associated with Katz (1988). Specifically, interviewees noted that increased safety and physical distance from customers created opportunities to develop customer-oriented business practices that may be impractical, unfeasible or even dangerous to pursue when dealing offline: 
Respondent (7): I try to provide the best products and service I can, when someone has a problem or claims [their order was] short on pills (as long as they have ordered from me before) I usually take them at their word.

Respondent (6): The street trade is a mess. I wanna provide labelled products, good advice and service, like a real business. Not sit in a shitty car park selling $\$ 10$ bags from a car window all day.

These sentiments highlight how cryptomarket vendors can experience significant nonmaterial, psychological rewards that differ markedly from the visceral thrills and public notoriety that are more typically associated with the offline drugs trade. In addition to some of the more typical seductions of crime (thrill, transgression, etc.), interviewees also reported a more nuanced kind of 'soft seduction' that results from feelings of safety and control, and manifests in courteous engagement with customers and the development of seller identities that are nested in a sense of professionalism more typically associated with the legal retailing economy. The above quotations therefore demonstrate an important point of differentiation between cryptomarkets and many offline drug markets in which the risk, if not reality, of violent predation remains a persistent threat. With no necessity to physically interact with either problematic customers or potentially violent competitors, cryptomarket vendors are freed from the necessity to present an image of violent deterrence that is often indispensable in such environments (Sandberg, 2012; Collison 1996). Instead, interviewees described being able to devote their time and energy to the cultivation of a more professional business identity centred around the provision of quality products and superior customer service.

The development of customer-oriented business practices was not only described by interviewees as personally satisfying, but is also necessary to attract customers in a hypercompetitive and reputation-sensitive online trading environment. Unlike sellers in offline drug markets, cryptomarket vendors are unable to rely on customers lacking choice amongst a limited number of sellers operating in a geographically restricted area (Aldridge \& Décary-Hétu, 2016). Instead, hundreds if not thousands of rival vendors - each with their own seller pages with associated customer feedback publicly visible - compete amongst a large but limited pool of customers. In such an environment, a premium is placed upon positive customer experiences which are reflected in publicly visible quantified metrics, thereby signalling reliability and attracting further patronage (Hardy \& Norgaard, 2015; Przepiorka et al., 2017).

We therefore see two complementary dynamics at work promoting the proliferation of professional business norms amongst cryptomarket vendors - on the one hand, the freedom to pursue a professional demeanour consistent with one's personal values, and on the other, a market structure that demands customer-oriented professionalism as a precondition for commercial success. These dynamics lend empirical support for Martin's (2018) 'gentrification hypothesis' which posits that the structural characteristics of cryptomarkets - particularly anonymity, geographical separation and customer feedback - may assist in displacing "potentially violent drug market norms in favour of more cordial relationships between market participants" (Martin 2018:1). 


\section{'Middle class' materialism: modest lifestyles and limited financial goals}

Despite the prospect of making larger profits than would typically be available to drug sellers operating offline, some interviewees articulated limited profit-oriented goals that centred around material security and the pursuit of a lifestyle that was comfortable rather than ostentatious, consistent with some social suppliers who become small-time sellers of recreational drugs (Coomber \& Moyle, 2014). For these respondents, online selling was perceived as providing a useful supplementary income rather than a full-time occupation:

Respondent (5): Initially it [selling on cryptomarkets] was to provide myself and friends with quality stuff. And then, as I was not a lab producer, it was more or less some kinda stock management which allowed me to have a bonus at the end of the month. But don't imagine big cars, jacuzzis etc hahah. It was more kind of paying rent, and use the bonus for tuition fees without ever putting me (or relatives) in the red. And from time to time a little extra like a music gear or so. I still had to go to university and so beside that.

Other vendors, who at the time they were interviewed operated medium-to-large-scale enterprises, emphasised a certain point of financial accumulation which would allow them to retire gracefully. These future endeavours were discussed in terms of self-realisation and personal fulfilment made possible through previous and on-going illicit earnings. One largescale vendor was looking forward to enrolling in graduate school, while a medium-scale vendor discussed his dream of becoming an organic farmer:

Respondent (1): I want to have enough money to never need to worry again, and I'm not that far from it. I would still work though. I made over half a million in the last 16 months. I also plan on getting a grad degree. [...] I want my spouse to go to school in Canada, and I want to move to Canada and raise my children there. I mainly just want enough that I can own a home in Canada and possibly go back and forth until I have citizenship. I don't need a 70,000 car to make me happy, so long as I'm meeting my own personal goals that's what matters.

RM: What are your goals?

Respondent (8): Biologic [organic] farmer. I want to do something that shares really love to the world, or bio restaurant. [...] Just make people happy with real things.

Underlying these modest and conspicuously mainstream financial goals was an awareness of the dangers associated with simply scaling up operations in response to customer demand and drifting unconsciously into a larger-sized enterprise than was originally intended. Instead, these vendors aimed to scale their operations within an ideal 'Goldilocks zone', one where sufficient profit could be maintained for a limited time without attracting unnecessary risk or other complications associated with managing additional personnel.

Respondent (4): I don't have enough time to make it a full time job... But as of now I'm content with customer bases and product moved. Not too much not too little.

Respondent (5): At a point I thought about bringing a friend of mine in but that just stayed a thought. Didn't want to involve anyone in that. 
These sentiments stand in further contrast to the short-term and hedonistic materialism associated with the classic seductions of crime and suggest that the cryptomarket vendors interviewed in this study hold more conservative and prudent attitudes towards both the scale of their operations, as well as to the size of their illicit earnings than is sometimes witnessed in other illicit drug markets, or what is assumed of its participants.

\section{Drift and techniques of neutralisation: ethical conduct, 'hard' vs 'soft' drugs, and a safer alternative to street selling}

Similar to offline sellers (Taylor \& Potter, 2013), some interviewees reported a casual, nonconscious move into selling drugs on cryptomarkets in manner consistent with Matza's (2009) concept of drift and Goldsmith \& Brewer's (2015) extension of it to cybercrime. For those interviewees who had no prior experience with offline selling, profit-oriented motivations, financial precariousness, prior experience as customers on cryptomarkets, as well as personal histories of non-commercial 'social supply' to friends and acquaintances, were all common precipitating factors that preceded a gradual drift towards selling drugs on cryptomarkets:

Respondent (5): When I studied, I used to get out with friends and slowly became "responsible" for the amusement stuff [...] but this is how it kind of started. Buy for friends and me, resell some extra and from there on I was able to accumulate a bit, resell etc. And all a sudden you're just in it.

RM: So you started buying [online], and then started selling. What motivated the switch?

Respondent (7): Number one would have to be money. I was in a position where I had just lost a job I had had for a while and I was in danger of losing my house, and I saw all these people vending and making what looked like huge amounts of money. I knew someone who diverted pharms and sold wholesale so I thought hey, I can do this.

Despite the material and non-material benefits associated with online selling, and a frequently expressed differentiation between their work and offline selling that takes place 'in real life', respondents also reflected on the consequences and ethical implications of selling drugs and made associated rationalisations that correspond broadly to the classic techniques of neutralisation (Matza, 2009). To reconcile the potentially negative effects of facilitating substance use, vendors would refer to their customers - or 'clients' as several professional sounding vendors referred to them - as being responsible consumers with whom they dealt ethically and honestly:

Respondent (9): At the end of the day selling coke is dangerous and people overdose... the difference is we actually care about our clients.

RM: Yeah. Does it affect the way you do business?

Respondent (9): It does but we sleep pretty good at night knowing that we work with a small group of semi responsible clients, we don't want to hurt anybody.

Respondent (10): We always supply clients, we don't cheat them... 
The techniques of neutralisation presented above are consistent with Matza's (2009) 'denial of responsibility', with interviewees noting that their customers are going to procure drugs regardless of whether they supply them or not, as well as with 'denial of injury' via a repositioning of selling on cryptomarkets as offering a safer consumer alternative to the offline drugs trade. Some vendors also offered an alternative rationalisation that is consistent with denial of injury by selling 'genuine', good quality drugs and by avoiding trading in 'hard' drugs which they considered to be (excessively) harmful:

Respondent (10): We are not hard drug sellers, but we think that people should have the right to access medications or drugs that are genuine and pure and properly dosed so that users stay safe and can enjoy getting high.

RM: Are there drugs you wouldn't sell?

Respondent (12): Yes. Heroin. Fentanyl. Crack. Coke. I don't do the hard shit.

RM: How come?

Respondent (12): If I don't use it I don't sell it. Those drugs ruin people's lives. They could kill themselves.

The sentiments expressed above should not, however, be subsumed solely under a notion of needing to justify anti-social behaviour. At times, the rationalisations employed by vendors were so successful in neutralising guilt that they began to be perceived as additional nonmaterial motivations rather than deterrents. The rationalisations presented below intersected with a political ethos prevalent on cryptomarkets as interviewees articulated their work as a way of 'sticking it to the man' or as form of pro-social libertarian resistance:

Respondent (10): Let's face it a LOT of people like getting high... It's human nature, but to ban it and make it criminal so that it's hard to get then you get poison and people die. [...] I can tell you that the use of darknet protects users from buying products that during traditional prohibition would likely kill much more people. It also takes drugs off the street, reducing some violent crime.

In the quotation above, opposition to the war on drugs offers a further rationalisation consistent with the technique of 'condemning the condemners' (Matza, 2009). Here interviewees would rationalise their selling via the claim that it is the regime of prohibition itself, rather than dangers inherent to illicit drug use, that poses the greatest risks to people's safety. Such discussions were also identified to be a central part of a more political engagement with cryptomarket drug trading (Munksgaard \& Demant, 2016; Martin, 2014a). Lastly, the statements presented below are consistent with the technique of 'appealing to higher loyalties' whereby vendors rationalise that they are engaged in pro-social or even 'heroic' behaviour that results in substantial benefits to their customers:

Respondent (6): This is our passion. It aint about money. Cannabis can heal. Cannabis can improve quality of life. 
Respondent (1): I was really genuinely devoted to the cause for a while.

RM: The cause?

Respondent (1): Yeah bro, spreading acid across the nation. . How many people are able to say they've spread almost half a million tabs of acid across the nation?

RM: Like that it's your goal?

Respondent (1): Of course. The guys during orange sunshine made like 3 million tabs and they are basically heroes to a generation. I want to be like that.

While undeniably self-serving, the techniques of neutralisation presented by interviewees should not necessarily be cynically interpreted. While it falls outside the scope of this research to assess either the validity of the rationalisations presented above or the relative harmfulness of online vs offline drug trading (see Aldridge et al., 2017; Martin, 2014a; 2018) many of the claims offered by interviewees are broadly consistent with a range of research that differentiates between drugs in terms of their potential to result in harms both to users and to broader society (Nutt et al., 2010), as well as the 'harm maximisation' and hugely deleterious effects associated with global drug prohibition (Werb et al., 2011).

\section{Discussion}

The literature on pathways into selling drugs proposes a variety of theoretical frameworks regarding the motivations that both facilitate and encourage offending. These include economic conceptualisations of risk and reward (Reuter \& Kleiman, 1986), the emotional and psychological seductions of deviant behaviour (Katz, 1988), and drift and techniques of neutralisation (Matza, 2009). In our cohort of cryptomarket vendors, motivations relating to each of these theories are not only present, but are also closely intertwined, with interviewee narratives continuously switching back and forth across different motivations and explanations. The pathways and motivations of interviewees therefore overlap between qualitatively different motivations which both encourage and shape their respective careers. This discussion synthesises the various theoretical perspectives and other issues presented in our analysis, elucidating the similarities, as well as the differences, between our research and the existing scholarship regarding pathways into selling drugs.

Our interviewees make clear that there are calculative economic motivations to either commence one's selling career on cryptomarkets or to move one's existing offline drug selling practice online. Of these, reduced risks, whether from law enforcement, customers or other offenders, along with the prospect of greater financial gains, are both central. Put simply, all interviewees reported that selling on cryptomarkets was far less risky and much more profitable than other types of drug selling. Despite feelings of increased safety, cryptomarket vendors still experienced immaterial rewards in the form of transgression, excitement and autonomy, in a manner consistent with Katz's (1988) seductions of crime. Interviewees also faced concerns associated with breaking the law and potentially harming others, as is broadly the case with offline sellers. These obstacles were circumvented in two principal ways: practically, via improving one's OPSEC; and psychologically, via self-rationalisations that broadly correspond to Matza's (2009) techniques of neutralisation. 
An initial reading of our analysis therefore reveals a range of empirical differences, but theoretical similarities with existing research. Indeed, many elements of interviewee narratives seem to confirm the notion that while there exists significant practical differentiation between online and offline types of drug selling, the motivations of vendors may be understood largely via a conventional synthesis of existing criminological theories. This perspective is misleading, however, with the applicability of these canonical theories, particularly Katz's (1988) seductions of crime, breaking down when considering some of the other claims made regularly by interviewees. Interviewees often emphasised the sense of professionalism and control enabled by their anonymity and geographical distance from sources of risk (customers, law enforcement, etc.). These immaterial benefits of the cryptomarket drugs trade - or 'soft seductions', as we term them - are experienced simultaneously with, but are qualitatively different from the visceral seductions of crime identified by Katz (1988). In contrast to a desire for romanticised risk and thrilling confrontation, the soft seductions of selling drugs on cryptomarkets are grounded in the reassuring, but stereotypically middle-class norms of risk aversion and conflict avoidance. Similarly, the limited financial goals and consciously moderate scale of operations pursued by interviewees provide an intriguing further point of contrast with Katz's (1988) offenders who 'burn through' illicit earnings in a hedonistic protestation against the mundanities of working-class life. While increased profit was a central motivator for interviewees, the lifestyle and materialism to which some aspired - comfortable house, sensible car, graduate education - are conspicuously middle class in nature.

These differences indicate a substantially different lived experience on the part of those who sell drugs via cryptomarkets and also suggest some differentiation in who is likely to become involved and persist in the online versus offline drug trades. All interviewees reported either no longer selling illicit drugs directly to consumers offline, or never being involved in offline drug selling in the first instance. While the limited number of respondents precludes the possibility of making representative claims of vendors as a whole, the unanimous and unambiguous preference in favour of selling online expressed by our interviewees provides strong preliminary support for the notion that at least some proportion of sellers on cryptomarkets are sufficiently risk and conflict averse that they would not be selling drugs but for their advent.

It is also evident that some of the benefits of offline dealing, namely peer recognition, do not by default yield the same satisfaction on the darkweb. Nevertheless, professionalised interactions, autonomy, running one's shop with customer service and satisfaction in mind, and gaining and maintaining a positive online reputation can be pleasurable and satisfying experiences. Regardless of whether vendors learn to appreciate these experiences once they commence their vending careers, are attracted by them to start with, or merely conform to established norms, all interviewees discussed these aspects in a positive light. As such, the 'gentrification' that Martin (2018) posits as a central characteristic of the cryptomarket drugs trade is not only the result of the practical idiosyncrasies of cryptomarket structures and operations (anonymity, customer feedback, geographical separation, etc.), but is also reproduced in the individual actions of cryptomarket vendors, who can experience genuine benefits from this reproduction. This suggests that the cryptomarket institution nurtures a mutually reinforcing cycle that attracts, encourages and rewards pro-social gentrified norms. 


\section{Conclusion}

This study employed innovative research methods to access an elusive, little understood, and steadily growing - and therefore increasingly important - cohort of online drug vendors. Our findings indicate that cryptomarket drug vendors are motivated by a variety factors that correspond to existing theoretical frameworks, namely economic calculation, drift and techniques of neutralisation, and seductions of crime. However, when discussing their motivations and pathways into their current careers, we find that while these frameworks have classificatory potential, individually they fall short in their ability to fully explain the reasoning of vendors. The seductions of crime, generally conceived of as being in opposition to middleclass values, are in fact inversed in our cohort, as vendors elaborate on the 'soft seductions' of non-violent economic interaction, honesty, professionalism, safety and control, and the pursuit of mainstream material goals. We suggest that these soft seductions attract and motivate people, many of whom would not otherwise be involved in the illicit drugs trade, to sell drugs on cryptomarkets, thus perpetuating and strengthening the 'gentrified' norms that are witnessed amongst this population. These findings indicate that cryptomarkets are differentiated from other forms of drug selling not only in terms of market structures and processes, but that these also influence and shape participant norms, priorities and sensitivities to both material and non-material risks and rewards in a manner different to that witnessed in offline drug markets.

\section{Funding}

This work was supported by an Australian Institute of Criminology research grant [50/16-17].

\section{References}

Aldridge, J., Stevens, A., \& Barratt, M. J. (2018). Will growth in cryptomarket drug buying increase the harms of illicit drugs?. Addiction, 113(5), 789-796.

Aldridge, J., \& Décary-Hétu, D. (2016). Hidden Wholesale: The drug diffusing capacity of online drug cryptomarkets. International Journal of Drug Policy, 35, 7-15.

Aldridge, J., Stevens, A., \& Barratt, M. J. (2018). Will growth in cryptomarket drug buying increase the harms of illicit drugs?. Addiction, 113(5), 789-796.

Bancroft, A., \& Scott Reid, P. (2017). Challenging the techno-politics of anonymity: the case of cryptomarket users. Information, Communication \& Society, 20(4), 497-512.

Barratt, M. J. (2012). The efficacy of interviewing young drug users through online chat. Drug and Alcohol Review, 31(4), 566-572.

Barratt, M. J., \& Aldridge, J. (2016). Everything you always wanted to know about drug cryptomarkets* (*but were afraid to ask). International Journal of Drug Policy, 35, 1-6.

Barratt, M. J., \& Lenton, S. (2010). Beyond recruitment? Participatory online research with people who use drugs. International Journal of Internet Research Ethics, 3(12). 
Barratt, M. J., Ferris, J. A., \& Winstock, A. R. (2016). Safer scoring? Cryptomarkets, social supply and drug market violence. International Journal of Drug Policy, 35, 24-31.

Barratt, M. J., \& Maddox, A. (2016) Active engagement with stigmatised communities through digital ethnography. Qualitative Research, 16(6), 701-719.

Baym, N. K. (2009) A call for grounding in the face of blurred boundaries. Journal of Computer-Mediated Communication, 14, 720-723.

Berridge, V. and Edwards, G. (1987) Opium and the People: Opiate Use in Nineteenth Century England, London: Yale University Press.

Blum, R. H. and Associates (1972) The Dream Sellers, London: Jossey-Bass Inc.

Bourgois, P. (2003) In Search of Respect (2nd ed.). Cambridge: Cambridge University Press.

Caulkins, J., \& MacCoun, R. (2003) Limited rationality and the limits of supply reduction. Journal of Drug Issues, 33(2), 433-463.

Christin, N. (2013) Traveling the Silk Road: A Measurement Analysis of a Large Anonymous Online Marketplace. Proceedings of the 22nd international conference on World Wide Web, 213-224.

Cole, C., Jones, L., McVeigh, J., Kicman, A., Syed, Q. and Bellis, M. (2010) Adulterants in illicit drugs: a review of empirical evidence Drug Testing and Analysis, 3(2):89-96.

Coomber, R. (2006) Pusher Myths: Re-Situating the Drug Seller, London: Free Association Books.

Coomber, R. (2015) 'A tale of two cities: understanding differences in levels of heroin/crack market related violence - a two city comparison', Criminal Justice Review, 40(1): 7-31.

Coomber, R., Moyle, L., Belackova, V., Hakkarainen, P., Hathaway, A., Laidler, K.J., Lenton, S., Murphy, S., Scott, J., Stefunkova, M., Van de Ven, K., Vlaemynck, M. and Werse, B. (2018) The Burgeoning Recognition and Accommodation of the Social Supply of Drugs in International Criminal Justice Systems: An Eleven-Nation Comparative Overview, International Journal of Drug Policy, 58: 93-103.

Coomber, R., Moyle, L., \& South, N. (2016). The normalisation of drug supply: The social supply of drugs as the "other side" of the history of normalisation. Drugs: Education, Prevention and Policy, 23(3), 255-263.

Coomber, R., \& Moyle, L. (2014) Beyond drug dealing: Developing and extending the concept of 'social supply'of illicit drugs to 'minimally commercial supply'. Drugs: education, prevention and policy, 21(2), 157-164.

Collison, M. (1996). In search of the high life: Drugs, crime, masculinities and consumption. The British Journal of Criminology, 36(3), 428-444.

Cross, J. C. (2000) Passing the buck: Risk avoidance and risk management in the illegal/informal drug trade. The International Journal of Sociology and Social Policy Social Science,20(910), 68-94.

Cunliffe, J., Décary-Hêtu, D., \& Pollak, T. A. (2019) Nonmedical prescription psychiatric drug use and the darknet: A cryptomarket analysis, International Journal of Drug Policy.

Cunliffe, J., Martin, J., Décary-Hétu, D., \& Aldridge, J. (2017) An island apart? Risks and prices in the Australian cryptomarket drug trade, International Journal of Drug Policy, 50, 64-73.

Curcione, N. (1997). Suburban snowmen: Facilitating factors in the careers of middle-class coke sellers. Deviant Behavior, 18(3), 233-253. 
Décary-Hétu, D., \& Giommoni, L. (2017). Do police crackdowns disrupt drug cryptomarkets? A longitudinal analysis of the effects of Operation Onymous. Crime, Law and Social Change, 67(1), 55-75.

Demant, J., Munksgaard, R., \& Houborg, E. (2016). Personal use, social supply or redistribution? Cryptomarket demand on Silk Road 2 and Agora. Trends in Organized Crime, 1-20.

Denton, B., \& O'Malley, P. (2001). Property crime and women drug sellers in Australia. Journal of drug issues, $31(2), 465-486$.

Dwyer, R., \& Moore, D. (2010). Beyond neoclassical economics: Social process, agency and the maintenance of order in an Australian illicit drug marketplace. International Journal of Drug Policy, 21, 390-398.

Goldsmith, A., \& Brewer, R. (2015). Digital drift and the criminal interaction order. Theoretical Criminology, 19(1), 112-130.

Hammersley, R. (2011) Pathways through drugs and crime: Desistance, trauma and resilience, Journal of Criminal Justice, 39, 268-272.

Hardy, R. A., \& Norgaard, J. R. (2016). Reputation in the Internet black market: an empirical and theoretical analysis of the Deep Web. Journal of Institutional Economics, 12(3), 515-539.

Hayward, K. (2007). Situational crime prevention and its discontents: rational choice theory versus the 'culture of now'. Social Policy \& Administration, 41(3), 232-250.

Hutchings, A., \& Holt, T. J. (2017). The online stolen data market: disruption and intervention approaches. Global Crime, 18(1), 11-30.

Jacinto, C., Duterte, M., Sales, P., \& Murphy, S. (2008). "I'm Not a Real Seller": The Identity Process of Ecstasy Sellers. Journal of Drug Issues, 38(2), 419-444.

Jacques, S., \& Wright, R. (2015). Code of the suburb: Inside the world of young middle-class drug sellers. Unversity of Chicago Press.

Katz, J. (1988). Seductions of crime: Moral and sensual attractions in doing evil. Basic Books New York.

Khoury, L., Tang, Y. L., Bradley, B., Cubells, J. F. and Ressler, K. J. (2010) Substance use, childhood traumatic experience, and Posttraumatic Stress Disorder in an urban civilian population, Depression \& Anxiety, 27(12): 1077-1086.

Ladegaard, I. (2019). Crime displacement in digital drug markets. International Journal of Drug Policy, 63, 113121.

Levitt, S. D., \& Venkatesh, S. A. (2000). An economic analysis of a drug-selling gang's finances. The quarterly journal of economics, 115(3), 755-789.

Lyng, S. (1990). Edgework: A social psychological analysis of voluntary risk taking. American journal of sociology, 95(4), 851-886.

Maddox, A., Barratt, M. J., Allen, M., \& Lenton, S. (2016). Constructive activism in the dark web: cryptomarkets and illicit drugs in the digital 'demimonde.' Information, Communication \& Society, 19(1), 111-126.

Martin, J. (2014a). Drugs on the dark net: how cryptomarkets are transforming the global trade in illicit drugs. Palgrave Macmillan.

Martin, J. (2014b). Lost on the Silk Road: Online drug distribution and the 'cryptomarket'. Criminology and Criminal Justice, 14(3), 351-367. 
Martin, J. (2018). Cryptomarkets, systemic violence and the 'gentrification hypothesis'. Addiction, 113(5), 797798.

Martin, J., Cunliffe, J., Décary-Hétu, D., \& Aldridge, J. (2018a). The international darknet drugs trade-a regional analysis of cryptomarkets. Australasian Policing, 10(3), 25.

Martin, J., Cunliffe, J., Décary-Hétu, D., \& Aldridge, J. (2018). Effect of restricting the legal supply of prescription opioids on buying through online illicit marketplaces: interrupted time series analysis. bmj, 361, k2270.

Martin, J. (2019). Revisiting Drugs on the Darknet: Key Issues and Debates in the Cryptomarket Drugs Trade. Drogen, Darknet und Organisierte Kriminalität.

Martin, J., Cunliffe, J., \& Munksgaard, R. (2019). Cryptomarkets: A Research Companion. Emerald Group Publishing.

Matza, D. (2009). Delinquency and Drift (5th ed.). New Brunswick: John Wiley \& Sons.

Moeller, K., \& Sandberg, S. (2015). Credit and Trust: Management of Network Ties in Illicit Drug Distribution. Journal of Research in Crime and Delinquency, 52(5), 691-716.

Moeller, K., \& Sandberg, S. (2019). Putting a price on drugs: An economic sociological study of price formation in illegal drug markets. Criminology, 57(2), 289-313.

Moeller, K., Munksgaard, R., \& Demant, J. (2017, 10). Flow My FE the Vendor Said: Exploring Violent and Fraudulent Resource Exchanges on Cryptomarkets for Illicit Drugs. American Behavioral Scientist, 61(11), 14271450.

Morselli, C., Décary-Hétu, D., Paquet-Clouston, M., \& Aldridge, J. (2017). Conflict Management in Illicit Drug Cryptomarkets. International Criminal Justice Review, 27(4), 1-18.

Morselli, C. (2001). Structuring Mr. Nice: Entrepreneurial opportunities and brokerage positioning in the cannabis trade. Crime, Law \& Social Change, 35(3), 203-244.

Moyle, L. and Coomber, R. (2015) 'Earning a Score: An Exploration of the Nature and Roles of Heroin and Crack Cocaine 'User-Dealers', British Journal of Criminology, 55, 534-555.

Munksgaard, R., \& Demant, J. (2016). Mixing politics and crime - The prevalence and decline of political discourse on the cryptomarket. International Journal of Drug Policy, 35, 77-83.

Nutt, D. J., King, L. A., \& Phillips, L. D. (2010). Drug harms in the UK: a multicriteria decision analysis. The Lancet, 376(9752), 1558-1565.

Ormsby, E. (2014). Silk Road. Palgrave Macmillan Australia.

Paquet-Clouston, M., Décary-Hétu, D., \& Morselli, C. (2018). Assessing market competition and vendors' size and scope on AlphaBay. International Journal of Drug Policy, 54, 87-98.

Przepiorka, W., Norbutas, L., \& Corten, R. (2017). Order without law: Reputation promotes cooperation in a cryptomarket for illegal drugs. European Sociological Review, 33(6), 752-764.

Reed, P. L., Anthony, J. C., \& Breslau, N. (2007). Incidence of drug problems in young adults exposed to trauma and posttraumatic stress disorder: do early life experiences and predispositions matter?. Archives of General Psychiatry, 64(12), 1435-1442. 
Reuter, P., \& Kleiman, M. A. (1986). Risks and prices: An economic analysis of drug enforcement. Crime and justice, 7, 289-340.

Sandberg, S. (2012). The Importance of Culture for Cannabis Markets: Towards an Economic Sociology of Illegal Drug Markets. British Journal of Criminology, 52, 1133-1151.

Schivelbusch, W. (1993) Tastes of Paradise: A Social History of Spices, Stimulants, and Intoxicants, New York: Vintage.

Soska, K., \& Christin, N. (2015). Measuring the Longitudinal Evolution of the Online Anonymous Marketplace Ecosystem. 24th USENIX Security Symposium (USENIX Security 15), 33-48.

Taylor, M., \& Potter, G. R. (2013). From "Social Supply" to "Real Dealing" drift, friendship, and trust in drug-dealing careers. Journal of Drug Issues, 43(4), 392-406.

Topalli, V., Wright, R., \& Fornango, R. (2002). Drug dealers, robbery and retaliation. Vulnerability, deterrence and the contagion of violence. British Journal of Criminology, 42(2), 337-351.

Tzanetakis, M. (2018). Comparing cryptomarkets for drugs. A characterisation of sellers and buyers over time. International Journal of Drug Policy, 56(0), 176-186.

Van Hout, M. C., \& Bingham, T. (2014). Responsible vendors, intelligent consumers: Silk Road, the online revolution in drug trading. International Journal of Drug Policy, 25(2), 183-189.

Werb, D., Rowell, G., Guyatt, G., Kerr, T., Montaner, J., \& Wood, E. (2011). Effect of drug law enforcement on drug market violence: A systematic review. International Journal of Drug Policy, 22(2), 87-94. 